\title{
Innovative Research on Solfeggio and Ear Training Teaching of Natural Artistic Conception Music
}

\author{
Shi Na \\ College of Music, Henan Finance University, Zhengzhou, 450046, China \\ *Corresponding Author.
}

\begin{abstract}
:
Solfeggio and ear training is the most important basic link in music education. Solfeggio and ear training education traditionally follows the mode of manual teaching with piano performance. With the progress of computer technology, more and more Solfeggio and ear training software began to appear, which not only had a certain impact on the traditional teaching, but also triggered the thinking and exploration of software application. Among them, Ear Master from Denmark is the most mainstream Solfeggio and ear training software in the current market. Because of its relatively perfect design and relatively powerful function, it has great application value in the current Solfeggio teaching practice. Although the subjective and objective deficiencies of Ear Master determine its role and positioning in teaching practice. The results show that Solfeggio and ear training can play a positive role as long as they are well used and follow certain principles. The research results can promote the development and improvement of traditional Solfeggio and ear training teaching.
\end{abstract}

Keywords: Ear Master, Solfeggio, Music education, Piano performance.

\section{INTRODUCTION}

Today, the popularization of computer technology and the development of Internet have brought an unprecedented great revolution to the world. Human society has entered the information age and network age [1-2]. Education, as an important form of human activities and the core form related to human survival and development, is naturally difficult to be immune from technological innovation and impact. Today's solfeggio is a core basic subject formed by music education after thousands of years of evolution and development to modern times. It can be called the "stepping stone" and "touchstone" of music learning [3].

From this point of view, far sighted music practitioners should be able to foresee that 
Article History: Received: 28 October 2021 Revised: 05 December 2021 Accepted: 10 January 2022 Publication: 28 February 2022

Solfeggio teaching is likely to undergo a major transformation from tradition to modernity and from manpower to computer in the future [4-5]. Music teaching and research personnel should actively respond to and participate in this trend, because Solfeggio teaching software must not only be the product of technology, but should be the combination of technology and art. Therefore, this paper analyzes and compares the main Solfeggio and ear training teaching software in the current market, defines the characteristics, advantages and disadvantages of such software, puts forward its own opinions and suggestions, and forecasts the future development trend. On the one hand, it is not only conducive to the modern transformation of traditional Solfeggio teaching, but also conducive to promoting the standardization, specialization and scientization of Solfeggio teaching software.

\section{DEVELOPMENT AND TRANSFORMATION OF TRADITIONAL SOLFEGGIO AND EAR TRAINING TEACHING}

\section{Deficiencies of traditional Solfeggio and ear training teaching mode}

The traditional Solfeggio teaching mode is the crystallization of predecessors' wisdom and experience. So far, it has been quite mature and perfect. However, the development of everything needs to keep pace with the times. At present, with the changes of various subjective and objective factors, the traditional teaching model has exposed some deficiencies.

(1) The timbre performance is relatively single. Listening to music is an indispensable part of Solfeggio and ear training teaching, which helps students improve their sense of music and response. One of the goals of Solfeggio and ear training teaching is to enable students to accurately and quickly identify different timbres through learning [6-8]. However, in the traditional Solfeggio teaching, the performance of timbre is often very weak. The reason is that the piano has a monopoly on teaching tools and media for a long time, so the timbre is usually single and unchanged. Although this situation is conducive to the unification and standardization of the teaching process, it is obviously not conducive to the progress and improvement of students in the long run.

(2) The music used in teaching is relatively single. However, in addition to the single timbre caused by relying too much on the piano, the traditional Solfeggio also has a relatively single problem in the selection of music, such as leaning towards "mainstream" music such as classical music and folk music. This is obviously not conducive to students to broaden their horizons, understand and recognize more rich and colorful music elements and forms. Solfeggio is a basic course [9]. At this stage, it is very beneficial for students to contact different music forms for the cultivation of music feeling and ability. However, traditional teaching often ignores this point, and often only uses a single music to meet the most basic teaching needs, which is lack of foresight and even sense of responsibility.

(3) The scale of teaching objects is limited. Generally speaking, for a 45 minute course, the 
Article History: Received: 28 October 2021 Revised: 05 December 2021 Accepted: 10 January 2022 Publication: 28 February 2022

number of students is best maintained at about five, which can ensure sufficient communication between teachers and students; When the number of students reaches more than ten, each student can only get one communication opportunity with limited time; Of course, when the number of people exceeds 20 , teaching is basically skimming the water and becoming a mere formality [10]. It is not easy to complete the teaching task. It is not easy to talk about the teaching effect and quality.

2.Solfeggio and ear training software: Modern Transformation of traditional mode

Specifically, the reasons for combining Solfeggio Teaching with computer software include:

(1) expand the teaching content, enrich and diversify it, so as to stimulate learning enthusiasm. On the one hand, digital music technology can greatly expand the timbre category of traditional musical instruments and human voice. Even the simplest digital music library can include hundreds of different timbres. Moreover, with the support of high technology, human beings have never "collected" timbres before. On the other hand, more kinds of music will be introduced into Solfeggio and ear training teaching. Especially the former, relying on modern technology, we can not only enrich and develop the traditional timbre, but also combine, adjust, create and synthesize all kinds of new and personalized timbre. If applied to Solfeggio and ear training teaching, it can greatly expand the teaching content. In addition, the introduction of pop music, rock music, electronic music and other kinds of music can make students have a sense of freshness, expectation, kindness and interest in Solfeggio and ear training, and learn more efficiently and energetically.

(2) It lightens the burden on teachers. An important value of Solfeggio and ear training software is that it relatively reduces the application of Solfeggio and ear training teaching technology in teaching practice. Through computer software, we can easily provide and obtain the music needed for teaching, which is made according to the teacher's own piano playing level and state, which greatly reduces the burden of teachers and improves the teaching efficiency.

(3) it promotes open teaching and avoids closure and rigidity. A prominent feature of computer software is that it is connected with the Internet, which can bring a huge amount of information. Therefore, with the use of Solfeggio and ear training software, teaching can no longer be limited to the classroom, and it is possible to break through the limitation of space. In addition to the enrichment of teaching contents mentioned above, music resources from different regions, nationalities and schools can be used for teaching. In teaching, it can also facilitate and timely communicate with others, learn from each other, understand the latest cutting-edge trends, greatly expand the vision of teachers and students, and avoid the traditional Solfeggio and ear training teaching from becoming a constant repetition.

\section{TEACHING APPLICATION VALUE OF EAR MASTER SOFTWARE}

1. Ear Maste: the main advantages of software. 
Article History: Received: 28 October 2021 Revised: 05 December 2021 Accepted: 10 January 2022 Publication: 28 February 2022

Through personal practice and combined with existing research results, the author believes that ear master software mainly has several advantages.

(1) It is less affected by objective factors. First, compared with the traditional piano or guitar, ear master software is hardly affected by objective factors in pitch. The first important and common objective factor is the natural environment. This advantage of Solfeggio and ear training software represented by ear master is, in a word, highly "standardized" and "stylized". This is the product of the industrialization of traditional education. No matter where you are and what your foundation is, as long as you have a computer, you can carry out or accept relatively standardized Solfeggio training with little difference. The second important and common objective factor is the performance level of teachers. As long as there is no program error or hardware failure in ear master software, the rhythm and melody played will always be smooth and accurate, and the instability or level limitation of manual teaching will be avoided.

(2) Relatively complete systematicness. Ear master software is designed based on a set of mature and perfect teaching methods, so it has the systematicness that ordinary similar software does not have. Each part and link are closely related and rely on each other, forming a close and integrated teaching system; Users enter this system, gradually promote it according to the requirements of the system, and finally achieve the goal.

(3) More perfect artificial intelligence. As a learning software, ear master is not limited to simple input or output information. One important reason why it has been widely praised and applied since its inception is the relatively perfect artificial intelligence (compatibility). The system will automatically save and prompt the user's learning process and results, so that the user can follow up his learning progress completely and in time, check and make up for deficiencies, and understand many simple and preliminary needs of the user to meet them.

\section{Main shortcomings of earmaster software.}

Ear master and other professional or non professional Solfeggio teaching software have the same advantages and disadvantages. From the subjective (software itself) and objective (external supporting) aspects, it can be found that this kind of software has the following shortcomings or deficiencies.

(1) There are some defects in the design. For example, ear master and other software have no standard sound a and lose this important benchmark, which will undoubtedly increase great and unnecessary difficulty for beginners and those with poor foundation. There is no technical difficulty in realizing the extended tone on the electronic keyboard. It only needs to set the long delay and gradually reduce it. But somehow, the designer didn't adopt it, which makes some users may fall into the situation that they can't understand, so they can only listen repeatedly, which will also cause some trouble to teachers' teaching.

(2) The operation is complex. The groups with high demand for software are precisely those older users. They learn Solfeggio and ear training through self-study, so they often have to turn to computer software, so they may encounter difficulties. If the software is only available in 
Article History: Received: 28 October 2021 Revised: 05 December 2021 Accepted: 10 January 2022 Publication: 28 February 2022

English or only in Chinese with low-quality folk translation, this difficulty will increase exponentially. Therefore, if the Solfeggio teaching software on the market wants to better serve the people who really need them most, it needs to be further humanized and concise in the design of operation and interface, so as to better promote and play a role.

(3) The learning method is relatively single. The way of practicing learning is relatively single, which is manifested in that it follows several inherent patterned programs, and the means are lack of plaques and not diversified enough. This is the inevitable weakness of artificial intelligence at this stage and the inevitable price of pursuing unification and standardization. Human teachers can obviously be more flexible in teaching and have a fixed routine, but they can also make corresponding adjustments according to the different situations of the audience.

\section{Application value of ear master software in teaching practice}

To sum up, combined with the advantages and disadvantages of ear master as a Solfeggio and ear training software, we can find that ear master software mainly has four application values for the current Solfeggio and ear training teaching practice.

First of all, it can greatly reduce the "threshold" of Solfeggio and ear training teaching, especially the requirements of material conditions, which is conducive to the development, promotion and popularization of Solfeggio and ear training teaching.

Secondly, we can "liberate" Solfeggio and ear training teachers to a certain extent, reduce their workload, and improve their teaching in terms of several items and quality.

Thirdly, it can enrich the content and form of Solfeggio and ear training teaching.

Finally, it can provide students with ways and tools for self-learning.

In short, the rise of ear master software represents a scientific and technological trend of music education. It also has its own uniqueness. It is of great value for the learning of Solfeggio and ear training, especially the practice of self-learning. If a single application is used, it should also be helpful to the special Solfeggio Teaching and bring new vitality and challenges.

\section{TEACHING APPLICATION OF EAR MASTER SOFTWARE}

\section{Exploration on the teaching application of ear master software}

In the chord training of ear master, chord recognition and chord transposition are mainly to play and decompose chords, although in the current actual teaching, teachers often focus more on cylindrical chords. The ear master provides us with convenience. For example, in a teaching, the system gives a chord 357 and gives the bass mi (Fig. 1), and the options are listed below for students to choose the nature (Fig. 2). At that time, the students judged that the chord was a minor triad through the sound effect, and judged that the minor triad formed above the bass mi was 357 according to the bass, so they got the correct answer. 


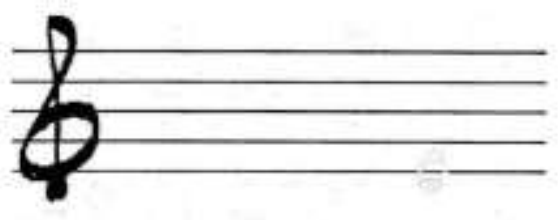

Fig 1: Bass mi

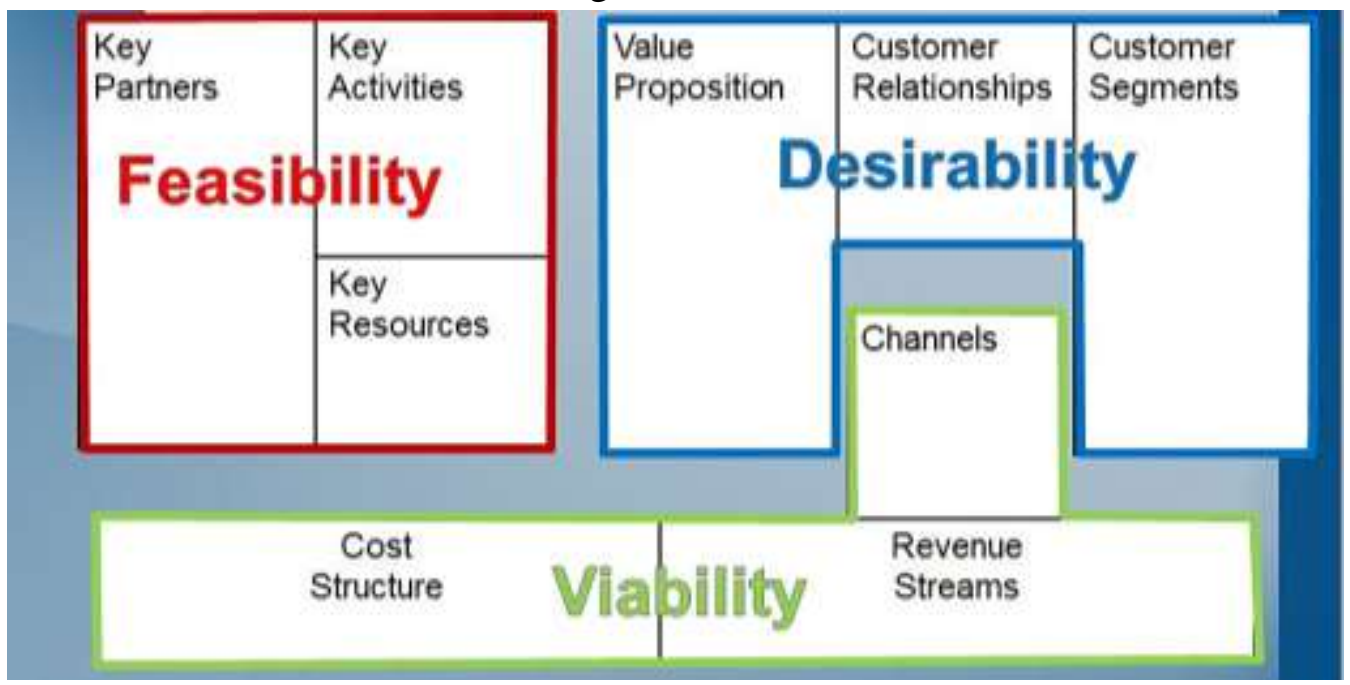

Fig 2: Minor triad

Rhythm training. In this part, earmaster can play a greater role. Because in traditional teaching, students play rhythm, and teachers listen with their ears; Compared with human hearing, the accuracy of computer receiving information (beating) is obviously higher. Not only that, the software also marks the rhythm of students playing fast or slow (Figure 3). Ear master's "rhythm" is actually quite similar to the traditional teaching methods. Teachers can not only use software teaching in class, but also students can consolidate their practice after class.

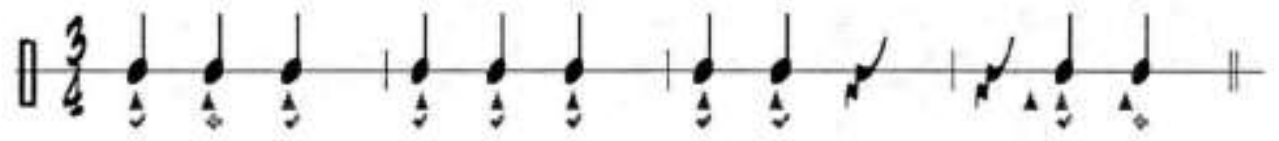

Fig 3: Rhythm training

2.Basic principles of teaching application of ear master software

Based on the exploration in teaching practice, the author believes that the application of ear master software should follow the following basic principles.

(1) Principle of appropriateness. The so-called principle of appropriateness contains two meanings: timeliness and Appropriateness. Among them, the so-called "timely" refers to the 
Article History: Received: 28 October 2021 Revised: 05 December 2021 Accepted: 10 January 2022 Publication: 28 February 2022

evaluation of earmate. The application of software should be to choose the appropriate time in teaching practice, not at will. Because this kind of software is like a double-edged sword. If used well, it can improve the efficiency and effect of teaching, add luster to teaching and help; If it is not used well, it may be counterproductive. Therefore, "an orange born in Huainan is an orange, and an orange born in Huaibei is a product". The use of Solfeggio and ear training teaching software should be timely and should not be blind. The so-called "moderation" means that the ear master software cannot be abused or "dominate".

(2) Principle of necessity. The principle of necessity is to prevent teachers from relying too much on computer software, relaxing their requirements and reducing their investment, especially emotional investment. Music is different from natural science. Music education needs full inner feelings and emotional input, otherwise it can not infect and mobilize students to enter the beautiful world composed of music; Although cold software can accurately output information, the "positive energy" transmitted to students by teachers through enthusiastic demonstration, detailed guidance and warm communication has unique value for the real improvement of students. Therefore, when manual teaching and computer software can only choose one of the two, a qualified Solfeggio teacher should decisively choose the former.

\section{CONCLUSION}

Ear master, as a Solfeggio and ear training software, has excellent design. It can not only be applied to self-learning, but also be used in the traditional Solfeggio and ear training teaching. Therefore, it can stand out among similar software and be widely recognized by the market. For such a professional music software with application value, we should take a positive view and try to make our traditional Solfeggio and ear training teaching obtain the support of modern science and technology and glow with new vitality.

At the same time, we must also face up to the shortcomings and limitations of ear master. In the teaching practice of Solfeggio and ear training, we should respect the tradition and law, grasp the discretion and methods, and deal with the relationship between good people and machines. Computer software is only a tool and means, the purpose is to serve people (teachers and students) and better promote the teaching and learning of Solfeggio and ear training.

In this way, when applying ear master and other computer software in practice, we can develop our strengths and avoid our weaknesses, avoid abandoning the basics, really play their positive role, and promote the development and improvement of traditional Solfeggio and ear training teaching.

\section{REFERENCES}

[1] KRIEG A.: Externalizing the Burden of War: the Obama Doctrine and Us Foreign Policy in 
Article History: Received: 28 October 2021 Revised: 05 December 2021 Accepted: 10 January 2022 Publication: 28

February 2022 the Middle East. Int Aff, 92(1), 97-113 (2016).

[2] ÁINE REGAN, RAATS M, SHAN L C, et al.: Risk Communication and Social Media During Food Safety Crises: a Study of Stakeholders' Opinions in Ireland. J Risk Res, 19(1), 119-133 (2016).

[3] SUNAR A S, SU W, ABDULLAH N A, et al.: How Learners' Interactions Sustain Engagement: A MOOC Case Study . IEEE T Learn Technol, 10(4), 475-487 (2017).

[4] BERMAN A H, BIGUET G, STATHAKAROU N, et al.: Virtual Patients in a Behavioral Medicine Massive Open Online Course (MOOC): A Qualitative and Quantitative Analysis of Participants' Perceptions. Acad. Psychiatry, 41(5), 1-11 (2017).

[5] OLSEN D S.: Adult Learning in Innovative Organizations. Eur J Educ, 51(2), 210-226 (2016).

[6] C. TAPIA, B. ABAJO, E. FELIU et al.: Profiling Urban Vulnerabilities to Climate Change: an Indicator-based Vulnerability Assessment for European Cities. Ecol Indic, 78, 142 (2017).

[7] S. LI, Z. SUN, M. TAN et al.: Changing Patterns in Farming-pastoral Ecotones in China between 1990 and 2010. Ecol Indic, 89, 110 (2018).

[8] C. VEllaithuRAI, A. SRIVASTAVA, S. ZONOUZ et al.: CPIndex: Cyber-Physical Vulnerability Assessment for Power-Grid Infrastructures. IEEE T Smart Grid, 6 (2), 566 (2015).

[9] HUSSEIN M ,DIEZ ROUX A V ,MUJAHID M S , et al.: Unequal Exposure or Unequal Vulnerability? Contributions of Neighborhood Conditions and Cardiovascular Risk Factors to Socioeconomic Inequality in Incident Cardiovascular Disease in the Multi-Ethnic Study of Atherosclerosis. Am J Epidemiol, 187(7), 1424-1437 (2018).

[10]DESMIT Z ,ELHABASHY A E ,WELLS L J , et al.: An Approach to Cyber-physical Vulnerability Assessment for Intelligent Manufacturing Systems. J Manuf Syst, 43(2), 339351 (2017). 